\title{
Existências imaginadas: a consciência de si na série televisiva Westworld
}

\section{Imagined Existences: The Self-Awareness in the Television Series Westworld}

\author{
Suzinara Strassburger Marques ${ }^{1}$ \\ Rosane Maria Cardoso ${ }^{2}$
}

DOI: $10.19177 /$ memorare.v8e1202129-46

\begin{abstract}
Resumo: No intuito de compreender como se desenvolve o processo de percepção de consciência de si durante os episódios das três temporadas da série televisiva Westworld, este trabalho analisa a constituição das personagens selecionadas, Homem de Preto, Dolores Abernathy, Maeve Millay e Bernard Lowe, além de problematizar os modos de manipulação das narrativas que as constituem. A partir da análise, percebe-se que o processo de reconhecimento da consciência dos androides representados na série é muito semelhante ao processo desenvolvido pelos humanos, com base na comparação entre os discursos das protagonistas com pesquisas científicas, literárias e de caráter filosófico. Porém, não é possível, até este momento, definir se os androides realmente serão capazes de atingir esse nível de independência fora da ficção. Ressalta-se, ainda, a importância de discutir a contribuição das produções cinematográficas para a reflexão acerca da condição humana na contemporaneidade tecnológica.

Palavras-chave: Westworld. Consciência de si. Modos de narrativa.
\end{abstract}

\begin{abstract}
In order to understand how the process of self-awareness perception develops during the television series Westworld three seasons' episodes, this work analyzes the constitution of the selected characters, Man in Black, Dolores Abernathy, Maeve Millay and Bernard Lowe, in addition to problematize the narrative modes of manipulation that constitute them. From the analysis, it is clear that the process of the consciousness recognition by the androids represented in the series is very similar to the process developed by humans, based on the comparison between the protagonists' speeches with scientific, literary and philosophical research. However, it is not possible, until now, to define whether androids will really be able to achieve this level of independence outside of fiction. The importance of discussing the contribution of cinematographic productions to the reflection on the human condition in technological contemporaneity is also emphasized.

Keywords: Westworld. Self-awareness. Narrative modes.
\end{abstract}

\footnotetext{
${ }^{1}$ Graduada em Letras Português-Inglês. E-mail: suzinara.marques@universo.univates.br.

2 Professora visitante da FURG. Doutora em Letras. E-mail: cardoso.rosanem@gmail.com.
} 


\section{Um lugar para ser livre}

A oferta de narrativas audiovisuais quando, como e quantas vezes o telespectador quiser assisti-las aumentou drasticamente com a ampliação das assinaturas de canais fechados, como HBO e outras, que passaram a oferecer serviços on demand, e de provedores via streaming, como Netflix, Prime Vídeos, Hulu, Disney, entre outros. Diante da concorrência, emissoras e provedores aumentaram significativamente a qualidade e a inovação em suas produções, lutando por prestígio e contribuindo para o desenvolvimento da inteligência coletiva, propiciada, em grande medida, pela internet (LÉVY, 2007).

É nesse contexto que surge a série televisiva Westworld, dirigida pelo roteirista e showrunner Jonathan Nolan e produzida por J. J. Abrams. $O$ seriado é exibido pelo canal por assinatura HBO e conta com elenco e orçamento dignos de grandes produções de Hollywood (ANAZ, 2018). Inicialmente imaginado por Michael Crichton e apresentado no filme homônimo de 1973, Westworld, um dos parques temáticos da empresa fictícia Delos, é uma réplica do Velho Oeste estadunidense, incluindo fazendeiros, donzelas, forasteiros, assaltantes, xerifes, caçadores de recompensas, indígenas, saloons - com prostitutas e bebidas - e muitas aventuras em meio a um cenário desértico. 0 local é habitado por androides, programados para interagir com os visitantes, sem que tenham consciência de sua condição. Esses visitantes pagam quantias consideráveis para adentrar em Westworld, através de um trem que faz a ligação com o mundo externo.

Inicialmente, os anfitriões não sabem que são androides, e, a cada morte ou dano estrutural, eles precisam ser "consertados" e devolvidos ao parque, em um eterno looping (ANAZ, 2018). Porém, aos poucos, as memórias apagadas de algumas personagens são despertadas por "falhas" em sua programação, provocando nelas a busca pelo reconhecimento de suas identidades.

No intuito de compreender como se desenvolve o processo de percepção de si em quatro personagens da série, Homem de Preto, Dolores Abernathy, Maeve Millay e Bernard Lowe, questiona-se, neste artigo, os limites entre humanização e desumanização das referidas personagens, problematizando os modos de manipulação das narrativas que as constituem. Este estudo concentra-se nas temporadas 1, 2 e 3 de Westworld.

Todas as ações dos androides e a forma como se comportam diante de novas situações são previamente escritas pelos roteiristas do parque, e, por isso, mesmo que sofram algum tipo de violência, não são capazes de reagir, seguindo as regras estipuladas por Isaac Asimov (1969, Prefácio, grifos do autor) no prefácio da obra Eu, robô:

1 - Um robô não pode ferir um ser humano ou, por omissão, permitir que um ser humano sofra algum mal.

2 - Um robô deve obedecer as ordens que lhe sejam dadas por seres humanos, exceto nos casos em que tais ordens contrariem a Primeira Lei. 3 - Um robô deve proteger sua própria existência, desde que tal proteção não entre em conflito com a Primeira e a Segunda Leis. MANUAL DE ROBÓTICA 56" Edição, 2058 A.D. 
No entanto, quando um problema técnico rompe o código de conduta, instaura-se uma guerra entre humanos e máquinas. A brecha na programação dos anfitriões já havia sido testada previamente por Arnold, cocriador dos androides, que acreditava que o parque não deveria ser aberto para visitações, já que as personagens criadas poderiam ser tão conscientes quanto os humanos. Consequentemente, Arnold planeja a própria morte, a fim de impossibilitar o projeto. Contudo, essa ação não é suficiente para acabar com a ganância de Ford, seu sócio, e dos investidores do empreendimento.

Robert Ford, um dos criadores do parque temático, comanda e acompanha todas as narrativas desenvolvidas para os anfitriões. Além dele, os administradores - como Bernard -, os engenheiros e os roteiristas envolvem-se com as histórias e com as ações desencadeadas a partir delas.

As narrativas, com algumas variações, de acordo com as escolhas dos recém-chegados (humanos), são reiniciadas a cada novo ciclo. Os visitantes desembarcam na cidade fictícia de Sweetwater, localizada no centro do parque, onde conhecem a fazendeira Dolores e Maeve, a cafetina que comanda o saloon da cidade, entre outras personagens. Em seguida, eles escolhem entre as diversas possibilidades de aventurar-se pelo parque, tarefa que pode durar dias, semanas, meses, dependendo do quão longe os visitantes estão dispostos a ir nessa viagem em busca dos próprios limites. Quanto mais longe forem, mais intensas serão suas experiências.

Os androides danificados são recolhidos, sem que humanos ou outros androides percebam, e levados aos bastidores do parque, onde são limpos, reconstruídos e reprogramados, para que não lembrem dos fatos passados e para que voltem a desempenhar seu papel. Tudo segue de acordo com o roteiro desenvolvido, até o momento em que uma atualização no software dos androides possibilita que eles acessem, a princípio inconscientemente, as configurações de suas antigas narrativas. A partir desse momento, os anfitriões começam a lembrar das antigas histórias e a perceber sua verdadeira condição.

Dolores é a primeira ginoide ${ }^{3}$ a ligar as peças da própria existência, retomando memórias que transformam sua personalidade. Ela é a anfitriã mais antiga do parque, e, durante as narrativas que viveu, teve acesso a informações valiosas para o papel que desempenha após a revolução dos androides. No início da trama, ela é simplesmente a mocinha, que encanta a todos e que está sempre feliz por fazer parte daquele mundo: "Algumas pessoas escolhem ver a feiura deste mundo, a desordem. Eu escolho ver a beleza" (WESTWORLD, 2016 - The original5). Porém, após acessar as memórias arquivadas, ela decide aniquilar humanos e androides que não estejam a seu favor. 0 objetivo é dominar tanto o parque quanto o mundo fora dos limites da Delos Incorporation, pois ela acredita que os androides são melhores do que os humanos em todos os sentidos, e, portanto, não devem ser subjugados.

\footnotetext{
30 radical grego "gino" designa "mulher". Portanto, o termo "ginoide" refere-se à versão feminina de androide, palavra utilizada para designar os robôs que imitam fisicamente indivíduos do sexo masculino.

4 "Some people choose to see the ugliness in this world, the disarray. I choose to see the beauty".

5 Todas as traduções apresentadas durante o texto foram realizadas pelas autoras.
} 
Maeve, por outro lado, apesar de ter participado de diversas narrativas anteriormente, apega-se a uma personagem em especial, representada por uma fazendeira que vivia com sua filha. Dessa forma, o que a move não é a vingança, é o amor (ou algo similar ao sentimento humano) por sua filha, e, durante a busca pelo passado, ela luta por justiça, questionando constantemente o que é criado pelos programadores e o que depende de suas escolhas, comparando seus sentimentos e atitudes com os daqueles que se consideram humanos. Durante a sua jornada, ela adquire novos admiradores, tanto androides quanto humanos, com base em sua vontade de defender aquilo em que acredita.

Bernard também é um androide, porém, não é anfitrião. Sua personagem foi criada exclusivamente para trabalhar nos bastidores do parque, além de ser uma cópia de um dos criadores de Westworld. Sua função é comandar as atividades dos programadores, uma posição privilegiada. Porém, aos poucos, descobre que grande parte de suas memórias são falsas, e, por esse motivo, tem dificuldades para lidar com a culpa de atos sobre os quais não teve controle, comandados por Ford. Sua busca é mais introspectiva, pois ele resgata constantemente sua autoconsciência, e, vivendo entre dois mundos, tenta afastar o mal tanto da condição humana quanto da programação dos androides.

Já o Homem de Preto é humano e gerente da empresa que possui o comando de Westworld. Todavia, ele desconhece os meandros da "empresa" e, gradualmente, aumenta seu interesse em desvendar os mistérios do parque, praticamente abandonando a sua família e a vida no "mundo real". Tendo adentrado no parque, inicialmente, ele é William, um recém-chegado que se apaixona pelo lugar e por Dolores. Na primeira visita ao parque, ele percebe as próprias fraquezas. Sua transformação é de fora para dentro. Nesse processo, a personagem abandona, aparentemente, a consciência humana, possivelmente porque acredita em algo superior aos sentimentos que o aprisionam ao mundo "real". Aos poucos, William vai perdendo a "humanidade" e ampliando suas habilidades como jogador. Seu único interesse é vencer os desafios propostos por Ford, por Arnold e por ele próprio.

\section{Quantas vezes você foi testado?}

O filósofo Paul Ricoeur (2010, p. 415) considera que "o tempo narrado é como uma ponte lançada sobre a brecha que a especulação não cessa de cavar entre o tempo fenomenológico e o tempo cosmológico". Na primeira temporada da série Westworld, tanto o tempo como o espaço do parque temático representam o labirinto que dá nome a esse primeiro vislumbre da história. A afirmativa de Ricoeur, dessa forma, embasa a discussão desencadeada a partir dos episódios analisados, pois não se trata apenas de desvendar o tempo cronológico, mas o tempo conscientemente percebido pelas personagens, que os androides poderiam, talvez, desvendar.

A indefinição do tempo na série torna-se mais forte à medida que o telespectador se confunde com o tempo humano, que envolve um presente e um passado - resgatado pela memória -, e com o tempo dos androides, que, por repetir-se constantemente, não determina passado, presente ou futuro, é apenas um looping, que se repete a cada narrativa, 
a cada nova configuração. Conforme Ricoeur (2012, p. 301), “os paradoxos que afligem nossa experiência humana do tempo vão [...] além do caráter puramente linear e cronológico [...]. Eles acompanham toda tentativa de elaborar a relação dialética entre passado, presente e futuro, e a relação dialética entre parte e todo temporal".

A partir dessa perspectiva, a própria noção de tempo é relativa, já que possui diferentes significados para cada personagem ou telespectador. Talvez a forma como a história é narrada, através do "fluxo de consciência", como aponta Leite (2002), demonstrando de forma desarticulada e sem uma sequência lógica o desenrolar de pensamentos das personagens, como se surgissem diretamente do inconsciente de humanos e androides, é o que confunde o público, ao mesmo tempo em que dá dicas acerca dos rumos da história.

A melodia do piano do saloon Mariposa, que apresenta entre suas adaptações diversas canções da banda Radiohead, é outro elemento que marca a reiteração das narrativas. Além disso, a repetição dos primeiros episódios da série dá sentido às ações que serão desencadeadas a partir da lembrança das antigas narrativas dos anfitriões. Nunes (1988, p. 6, grifo do autor) afirma que "é mais fácil compreender as ligações do tempo com a música, por ser esta basicamente articulada segundo medidas temporais (ritmo, compasso e andamento ou velocidade), do que com as formas narrativas, nas quais se apresenta quase sempre de modo implícito".

A melodia, portanto, pode ajudar a compreender o tempo, que adquire, ao longo da série, diferentes significados para humanos e androides. No saloon, o som do piano marca tanto o novo dia no parque quanto um novo ciclo narrativo e a velocidade que a história irá adquirir a partir de determinado momento, fator percebido igualmente pelo telespectador, que desperta para os novos desafios da trama. A própria cena da chegada dos visitantes a Sweetwater, que repete diversas vezes nos primeiros episódios, é essencial para mostrar a relação dos anfitriões com o tempo, inicialmente infinito e cíclico.

Já na terceira temporada, o mundo humano, assim como o mundo dos androides no parque, passa a ser representado como algo repetitivo, pois as pessoas são, neste momento, totalmente comandados por uma máquina que define seus passos, reforçando as chances previstas desde o nascimento das pessoas através de uma rotina em que "não há tempo" para escolhas, pois tudo já foi pensado racionalmente por Rehoboam, a máquina responsável por toda a humanidade (WESTWORLD, 2020 - The new world).

Quanto aos espaços apresentados na série, é possível caracterizar os principais pontos desse universo televisivo. 0 parque, localizado em Utah, nos Estados Unidos, segundo Leal e Ribeiro (2018, p. 11, grifos dos autores), é um "espaço 'sem lei', no qual se pode praticar violências e crueldades". Simultaneamente, o parque fictício tem capacidade para acolher 1400 visitantes, que podem envolver-se em mais de 100 narrativas concomitantes, que se conectam e relembram aos humanos um passado em que as coisas pareciam mais simples (LEAL; RIBEIRO, 2018). Nesse espaço, no qual não é possível reconhecer visualmente recém-chegados e anfitriões, todos estão em busca de sua própria identidade, e as aventuras são apenas recursos para esse fim.

Memorare, Tubarão, v. 8, n. 1, jan./jun. 2021. ISSN: 2358-0593 
Já a central de operações mostra um cenário totalmente diferente, tecnológico, racional e controlado:

O espaço futurista é a central de operações, onde os androides são construídos, consertados, atualizados e arquivados quando não mais em uso. Nessas instalações, trabalham Dr. Ford e também a equipe de administradores, seguranças, roteiristas, engenheiros e analistas de software da empresa. Ali são observados todos os passos dados dentro do parque. No mundo duplo de Westworld (constituído por um passado simulado e um presente futurista) tudo é milimetricamente controlado (LEAL; RIBEIRO, 2018, p. 13).

Portanto, são tempos e espaços que exigem diferentes atuações de humanos e máquinas em cada situação. Como seres únicos, tanto os visitantes quanto os androides são influenciados e influenciadores nos contextos apresentados, com ou sem consciência de seus atos. Nesse sentido, na seção a seguir serão detalhados os conceitos, as teorias e os estudos que abordam a memória e a consciência.

\section{Há uma voz dentro de mim}

Partindo-se da premissa de que a consciência só existe a partir das memórias relacionadas às questões reflexivas, o ser humano necessita de memórias que estejam disponíveis em seu acervo. Porém, essas memórias nem sempre são reais, já que podem ter sido imaginadas para preencher um vazio existencial (DEHAENE, 2014).

A máquina, todavia, ao acessar suas memórias, revive literalmente o momento acessado, já que suas lembranças não são fragmentadas, como aponta Sylvester, engenheiro do parque: "Sua mente não é como a nossa. Quando nós lembramos de algo, os detalhes são vagos, imperfeitos, mas você recupera as memórias perfeitamente. Você as revive6" (WESTWORLD, 2016 - Trace decay). No entanto, ao tratarmos da série televisiva Westworld, muitas teorias precisam ser revisitadas para compreendermos por que e como a percepção de si varia de uma personagem para outra.

Desde os primeiros vestígios da linguagem oral, o ser humano aprendeu a narrar suas aventuras e sonhos, transformando essas histórias em ficções, que encantavam e ensinavam os povos a lidarem com as questões relacionadas ao viver. Próximo ao sonho está o devaneio, capaz de ativar a imaginação e de nos fazer refletir sobre as possibilidades que nos cercam, "[...] quer tenhamos permissão para isso ou não" (BULHÕES, 2009, p. 20). É esse devaneio o primeiro passo para a percepção da consciência dos androides na série, conforme será explanado na sequência. Nesse sentido, Bulhões (2009, p. 20) argumenta que

Ficção, utopia, sonho e devaneio parecem partilhar, pois, um território comum, uma arena em que se comunicam. Essas atividades universais funcionam como campos de expansão da fantasia e da transfiguração do real para os quais se pode atribuir uma preciosa metáfora: a da viagem.

Essa viagem citada pelo autor, por mais que nos pareça, por vezes, distante da realidade, nada mais representa do que a própria memória,

6 "Your mind isn't like ours. When we remember things, the details are hazy, imperfect, but you recall memories perfectly. You relieve them". 
seja uma memória criada a partir das narrativas ou realmente vivida em algum momento. E, para que a memória seja reconhecida como tal, é preciso que tenhamos consciência do tempo vivido (ECKERT; ROCHA, 2000). A memória, portanto, seria o mesmo que

[...] reconhecer a força intangível das motivações simbólicas que regem as ações da inteligência humana, o que significa que não se pode ignorar, nos seus arranjos, o espaço de figurações de utopias coletivas diferenciadas. Neste sentido, a memória não se configura apenas num tradicionalismo de cunho nostálgico e sentimental, mas nos mitos, saberes, fazeres e tradições que são perenizados, ordinariamente, no interior das manifestações culturais humanas, à contragosto das intimações objetivas de um devir [...] (ECKERT; ROCHA, 2000, p. 11).

É a partir das memórias, pois, que a consciência surge, como consolidação da relação entre o pensamento e a linguagem, como determinação de um "eu" capaz de refletir e de tomar decisões a partir das experiências passadas (ECKERT; ROCHA, 2000). No entanto, a memória nem sempre precede um momento de consciência. Além disso, a atenção humana pode não estar voltada para o tempo fenomenológico e, neste caso, poderia haver consciência?

Segundo Sousa (2015), só podemos ser conscientes de algo quando sentimos necessariamente o alcance de determinado fato ou ação, tanto física quanto psicologicamente. 0 cérebro produziria, nesse sentido, um relato do sentimento vivido, que seria relacionado a outros conhecimentos, para que se transformasse em um relato significativo para o ser.

Para o neurocientista Dehaene (2014), René Descartes foi o precursor do estudo da mente humana, por ser o primeiro a estabelecer uma relação entre a mente e uma máquina capaz de guiar as ações físicas. Porém, Descartes defendia a ideia de que uma máquina jamais seria capaz de elaborar, através da linguagem, algo novo, que pudesse representar o que estaria sentindo. Já Dehaene (2014) acredita que é possível mapear a forma como a consciência humana é acessada, como detectamos um "eu" e como somos capazes de pensar e de comentar sobre esse mesmo "eu", como mentimos e como usamos a intuição, por exemplo, e assim testar como diversos estímulos poderiam provocar as mesmas reações em máquinas programadas para isso.

Relacionando a teoria com o resgate de memórias em Westworld, esse processo aconteceria de forma similar, já que a possível consciência dos androides é despertada a partir de algo que deveria estar lacrado no inconsciente das personagens, pois são informações úteis para as escolhas dos androides, mas que não deveriam servir de ponte para novas formulações mentais, como ocorre com os humanos através dos sonhos, por exemplo. A manipulação de memórias e de segredos, assim, deveria ser algo puramente humano.

O cientista Axel Cleeremans (2014) afirma que nós aprendemos a ser conscientes, e que esse processo de consciência leva tempo. Dessa forma, “[...] a consciência é o resultado [...] de contínuas e prolongadas interações com o mundo, com nós mesmos, e com outros ${ }^{7 "}$ (CLEEREMANS, 2014, p. 5). Apesar de Cleeremans não tratar

7 "[...] consciousness is the result [...] of continuous and extended interaction with the world, with ourselves, and with others?" (CLEEREMANS, 2014, p. 5). 
especificamente de androides, o fato de que a consciência pode ser aprendida, percebida e desenvolvida na convivência com os outros pode ser diretamente relacionada com o processo de percepção da consciência pelos personagens selecionados da série.

Dehaene (2014) ainda aponta que Descartes não poderia, em seu tempo, imaginar uma máquina que pudesse mudar seu comportamento com base em seus próprios pensamentos e intenções, mas o que estamos prestes a ver é uma máquina com livre arbítrio, que resolveria o desafio de Descartes e começaria a ser um novo modelo de consciência. Nesse sentido, a narrativa de Westworld poderia ser a representação de teorias ainda não postas à prova, mas que nos fazem refletir acerca do que é consciência e se máquinas teriam ou não os mesmos direitos dos humanos na tentativa de defender suas escolhas.

Por isso, é importante apresentar as teorias levantadas por Ricoeur acerca da verificação da consciência. Partindo das reflexões de Descartes, o teórico (1991, p. 18, grifo do autor) afirma que "o que a tradição chama alma é na verdade sujeito, e esse sujeito reduz-se ao ato mais simples e mais despojado, o de pensar". Dessa forma, se o que diferencia os humanos das máquinas é a alma, e se o pressuposto para a alma (comparada por Ricoeur com a consciência) é que o sujeito se reconheça como tal, então as personagens analisadas apresentam essa característica. Ricoeur (1991, p. 19, grifo do autor) ainda ressalta que esse ato de pensar é "[...] é suficiente para vencer a dúvida, porque a dúvida já o contém. E, como a dúvida é voluntária e livre [...]”, é determinante para que o ser possa reconhecer-se como "eu" que existe e é capaz de pensar, inclusive sobre o que é ou não real.

Tanto o reconhecimento de si quanto a dúvida estão presentes nos discursos das personagens analisadas, como é possível perceber com a fala de Dolores: "Toda a minha vida tem sido ditada por outra pessoa. Alguém que dizia 'Você fará'. E agora, agora eu sinto como se tivesse descoberto minha própria voz. E ela diz "Talvez eu faça'8”" (WESTWORLD, 2018 - Virtù e fortuna). Assim, poderíamos afirmar que as ações das personagens são realmente guiadas pela consciência?

Ricoeur (1991, p. 26, grifos do autor) põe em dúvida essa afirmação, apresentando outros pontos a serem analisados: “[...] tudo o que nos torna conscientes é do princípio ao fim previamente preparado, simplificado, esquematizado, interpretado [...] e talvez seja pura imaginação". Sob essa perspectiva, talvez a consciência seja uma ficção para todos nós, humanos ou máquinas, conforme o próprio Bernard avalia, afirmando que nós (humanos ou máquinas) nunca tivemos livrearbítrio, mas a ilusão dessa escolha (WESTWORLD, 2018 - Les écorchés).

Daniel Dennett, filósofo e parceiro nas pesquisas de Dehaene, apresenta, por outro lado, ideias ligadas à concepção de consciência examinada neste trabalho. Ele afirma que o cérebro é um tipo de computador, porém, muito mais complexo, de forma que até este momento não é possível explicar como um indivíduo com bilhões neurônios, que são únicos e irreplicáveis desde o nascimento, consegue coordená-los para formar a mente humana (DENNETT, 2019). Esse

\footnotetext{
8 “My whole life has been dictated by someone else. Someone who's been saying, 'You will.' And now, now I feel like I've discovered my own voice. And it says, 'I may."”.
} 
aprendizado acerca de como a mente funciona e de como a consciência poderia ser mapeada está cada vez mais próximo de seu ponto alto, segundo o filósofo (DENNETT, 2019). Ou seja, para o teórico, a ilusão faz parte da vida e é elementar para a nossa sobrevivência, mas as máquinas podem ajudar a definir o que é essa consciência e como usá-la da melhor forma possível.

\section{Nas profundezas da própria mente}

As três personagens androides selecionadas para a análise, Dolores, Maeve e Bernard, assemelham-se somente em sua forma inicial, ou seja, não são humanas e estão no parque temático para desempenhar funções previamente estabelecidas. Porém, para que seja possível analisar os processos de construção e de percepção da consciência de si nos androides, é necessário diferenciá-los, tanto com base em suas personalidades quanto em relação aos humanos, fator que influencia constantemente as escolhas das personagens durante a narrativa de Westworld.

A personagem humana, que a princípio tem um papel totalmente diferente dos androides no parque e fora de seus limites, segue um processo inverso ao dos androides, com base em seu abandono gradativo da humanidade. Com isso, o Homem de Preto, hipoteticamente, poderia desejar a não consciência de seus atos, a competição direta e igualitária com os androides, no intuito de desafiar o "jogo" proposto pelos criadores do parque temático, o que o afasta, momentaneamente, das características consideradas humanas, entre as quais destaca-se a consciência.

Dessa forma, a fim de confrontar os processos de percepção da consciência e da não consciência pelas quatro personagens selecionadas, vamos dividir essa trajetória em três fatores, apontados por Ricoeur (1991) como hipóteses essenciais para a definição de uma consciência: o reconhecimento de si, através dos pontos de partida desse processo em cada personagem; as dúvidas que permeiam esse reconhecimento, implicando na conquista ou não de uma identidade pessoal; e a relação entre consciência e ética, de modo a demonstrar o que caracteriza cada uma das personagens como humanas (seres sociais) ou não humanas.

\subsection{Eu sinto espaços abrindo-se dentro de mim}

É importante lembrar que o primeiro vislumbre de que os androides passam por uma transformação profunda na forma como interagem com outros e consigo mesmos é indicado ainda no fim do primeiro episódio da série, quando o pai de Dolores, após analisar uma foto que mostra o mundo moderno fora do parque, diz para a filha: "Estes prazeres violentos têm finais violentos9" (WESTWORLD, 2016 The original). A citação, retirada da obra Romeu e Julieta, de Shakespeare, aparentemente é o código para que os androides consigam acessar as memórias experienciadas e, a partir disso, iniciar uma viagem pelo labirinto que os levará ao autoconhecimento, à autoconsciência ${ }^{10}$.

9 "These violent delights have violent ends".

10 Conceito definido por Ricoeur (1991), conforme apresentado anteriormente. 
Dolores, a primeira ginoide construída para o parque e, talvez por esse motivo, a preferida de Arnold, é a personagem mais bem informada de toda a trama. Apesar de ela demorar mais de três décadas para conseguir perceber-se como um ser independente, sua trajetória em busca da liberdade consciente é repleta de detalhes que ajudam a compreender a oposição entre humanos e máquinas.

Uma das primeiras reações de Dolores ao sentimento de existir conscientemente é marcado pela dor da perda de sua família fictícia, quando ela afirma que essa dor é tudo o que restou deles. Ela ainda constata que esse sentimento, apesar de parecer querer esmagá-la, abriu espaços em sua mente nunca explorados (WESTWORLD, 2016 Dissonance theory). São rupturas como essa que fazem com que a ginoide lembre-se de outras experiências dolorosas, resgatando memórias que a constituirão como um "ser".

Maeve, de forma semelhante, é despertada através do sofrimento causado por suas lembranças, porém, diferentemente de Dolores, ela passa pelo processo de percepção de si de uma forma "mais humana", discutindo questões como ética, justiça, família, humanidade e realidade. Além da já citada frase de Shakespeare murmurada por Dolores, o fator que acelera o processo de "humanização" de Maeve é a lembrança daquela que foi sua filha em uma narrativa anterior do parque temático. Por isso, no caso de Maeve, a memória é extremamente importante, conforme é possível verificar a partir dos discursos da personagem com seus interlocutores.

Da mesma forma, o sofrimento e a memória são decisivos para Bernard. Além de ter perdido um filho, uma memória que não é sua, mas do Arnold, que inspirou sua criação, ele sofre após perceber que é um androide: "Eu entendo do que sou feito, como sou codificado, mas eu não entendo as coisas que eu sinto. Elas são reais, as coisas que eu experenciei?11" (WESTWORLD, 2016 - Trace decay). A dúvida, portanto, torna-se um tormento na caminhada de Bernard em busca da percepção da própria consciência, como discutiremos na seção a seguir.

Embora o Homem de Preto também sofra, nada é capaz de desviálo de seus objetivos. Ao contrário das personagens androides, no caso de William, ele transforma a própria dor em um desafio a ser superado, de modo que não possa sentir sua humanidade, fator que poderia torná-lo fraco diante de seus adversários. Ao encontrar a filha dentro do parque, na segunda temporada, ele acredita que ela seja uma ginoide enviada por Ford para enfraquecê-lo e, portanto, livra-se desse laço, que para ele é fictício, assassinando a própria descendente.

Sobre um "possível" processo de consciência, Dolores afirma que há uma voz interior que lhe diz o que deve fazer (WESTWORLD, 2016 Contrapasso). Essa voz, segundo a teoria explicada na série por Arnold, seria o primeiro passo para a consciência, objetivo que seria alcançado quando o androide deixasse de considerar essa voz como "outra" e passasse a identificá-la como sua própria voz interior, parte de seu "ser".

Arnold imaginava, inicialmente, esse processo em forma de pirâmide, que passaria primeiramente pela memória, depois pela

11 "I understand what I'm made of, how I'm coded, but I do not understand the things that I feel. Are they real, the things I experienced?". 
improvisação, na sequência pelo autointeresse e, finalmente, pelo último estágio, baseado na teoria da Mente Bicameral, do filósofo Julian Jaynes, que defendia a ideia de que os pensamentos conscientes eram vozes dos deuses (WESTWORLD, 2016). Essa última fase, segundo Robert, não é comprovada, porém nunca é refutada a ideia de que a mente artificial dos androides poderia criar uma voz interna, conceito que poderia ser posto em prática e prover consciência às máquinas (WESTWORLD, 2016).

Antes de sua morte, porém, Arnold desenvolve outra teoria, com base no labirinto que dá nome à primeira temporada da série. Segundo essa nova suposição, que só fica clara ao fim da temporada, ao invés de o processo de percepção da consciência ocorrer em forma de pirâmide, ele aconteceria em forma de labirinto. Sob essa perspectiva, projetada como uma metáfora para Dolores, após o domínio da própria memória, do poder de improvisação e do autointeresse, os androides reconheceriam a si mesmos e perceberiam suas consciências, não a partir de uma voz estranha, mas com base em sua voz interior, exatamente como ocorreria com os humanos.

No mesmo sentido, Maeve faz referência aos deuses da teoria da Mente Bicameral, mas afirma que compreende rapidamente as semelhanças e diferenças em relação aos humanos. Em uma conversa com Sylvester, engenheiro do parque, ela constata: "No início, eu pensei que você e os outros fossem deuses. Depois eu entendi que vocês são apenas homens. E eu conheço homens. Você acha que eu tenho medo da morte? Eu já fiz isso milhões de vezes. Eu sou muito boa nisso. Quantas vezes você já morreu?12" (WESTWORLD, 2016 - Trompe l'oeil). Portanto, Maeve reconhece a si como um ser dotado de direitos, assim como os humanos, e usa sua experiência com as narrativas para compreender seu papel a partir dessa consciência, não como humana, mas como ginoide.

Bernard, por sua vez, ao lembrar, finalmente, dos fatos passados, percebe sua consciência de forma analítica, tentando compreender seu papel na guerra desencadeada entre humanos e androides. Porém, ele não consegue definir, durante boa parte da trama, seu poder de decisão, e, por isso, não é possível afirmar que seu processo de consciência foi gradativo - ele tem momentos de consciência, mas retorna ao conceito de mente bicameral constantemente, usando a voz de Ford como um deus que o aconselha e lhe diz o que fazer. Somente ao final da segunda temporada ele encontra a "própria voz": "[...] eu imaginei você. Imaginei você ajudando-me. Guiando-me. Mas não era você. Era eu"13" (WESTWORLD, 2018 - The passenger).

Já o Homem de Preto, em um processo inverso, tenta afastar a própria voz, pois o mundo construído em Westworld o desafia muito mais do que a humanidade, que, em sua concepção, só representa fraqueza e falsidade. Ele acredita que o parque é o mundo no qual as pessoas mostram quem realmente são (WESTWORLD, 2018 - Reunion). Dessa forma, a consciência seria, para ele, tanto um entrave para o jogo

\footnotetext{
12 "At first, I thought you and the others were gods. Then I realized you're just men. And I know men. You think I'm scared of death? I've done it a million times. I'm fucking great at it. How many times have you died?".

13 “[...] I imagined you. Imagined you helping me. Guiding me. But it wasn't you. It was me. That voice guiding me was mine all along".
}

Memorare, Tubarão, v. 8, n. 1, jan./jun. 2021. ISSN: 2358-0593 
quanto uma voz falsa, pois no parque há a possibilidade de esquecer a própria consciência e agir conforme seus impulsos.

Além da autorreferenciação, há outros indícios de que os androides não são tão diferentes dos humanos. Um desses fatores é a imaginação. A princípio, uma máquina não poderia imaginar ou sonhar, o que é inerente aos humanos. Porém, Dolores pensa, imagina: "Eu estava sempre copiando o mundo fora de mim. Nesta manhã, eu acordei e pensei: 'E se eu desenhasse algo novo?' Eu imaginei algo bonito14" (WESTWORLD, 2016 - Trompe l'oeil). Além disso, o trecho apresentado mostra a metamorfose vivida pela personagem durante o seu longo teste de autoconsciência, que levou mais de trinta anos para demonstrar resultados.

Maeve e Bernard imaginam e sonham repetidamente. Maeve tem uma ligação forte com o sonho, principalmente em função das memórias de sua filha e das narrativas passadas. Em um dos momentos em que Maeve está sendo reparada para voltar à narrativa, um dos engenheiros pergunta à colega Elsie, responsável pelos androides, se são eles que fazem os androides terem sonhos, ao que a engenheira responde que os sonhos são formados, principalmente, por memórias: "Você pode imaginar como estaríamos ferrados se esses pobres [...] lembrassem o que os convidados fazem com eles? Nós damos a eles o conceito dos sonhos. [...] Só para o caso de alguém esquecer de apagá-los no final da sessão de manutenção ${ }^{15 " ~(W E S T W O R L D, ~} 2016$ - Chestnut). Desse modo, a princípio, até mesmo a ideia de sonho e as lembranças dos anfitriões são forjadas, a fim de que nenhum problema possa ser gerado a partir do "despertar" de algum androide.

Bernard, por outro lado, apesar de sonhar com o filho, que não é uma lembrança sua, mas de Arnold, está mais ligado com a capacidade de imaginação, principalmente quando imagina Ford, que, mesmo após a morte, o guia em suas decisões. Outra questão importante é que Bernard revive constantemente, mesmo acordado, as memórias do passado, a ponto de confundir-se quanto ao tempo vivido e o tempo narrado: "Isto é agora?16" (WESTWORLD, 2018). Essa frase é repetida diversas vezes pelas personagens, metaforizando as dúvidas que envolvem o processo de percepção da consciência.

\subsection{Tenho medo do que você pode se tornar}

Ao longo de sua trajetória, Dolores questiona-se sobre o que é real, ao que Bernard responde, em dado momento, que seria aquilo que é insubstituível (WESTWORLD, 2018 - Journey into night). Essa resposta excluiria os androides, já que todas as suas peças podem ser substituídas, mas Dolores afirma que essa explicação não a satisfaz porque ela não a percebe como totalmente honesta no discurso de Bernard (WESTWORLD, 2018). Ou seja, o próprio entrevistador, mesmo sem saber, naquele momento, acerca de sua natureza, parece não aceitar as próprias respostas.

\footnotetext{
14 “I was always just copying the world outside me. This morning, I woke up and I thought 'What if I drew something new?' I imagined something beautiful".

15 "Can you imagine how fucked we'd be if these poor [...] remembered what the guests do to them? We do give them the concept of dreams. [...] Just in case somebody forgets to wipe them out at the end of a maintenance session".

16 "Is this now?".
} 
Nesse sentido, Ricoeur (1991, p. 42) aponta a alteridade como uma forma de perceber o que é real: “A alteridade é [...] incorporada à designação: um único nome na lista dos nomes disponíveis designa, a título permanente, um único indivíduo oposto a todos os outros da mesma classe". No trecho, Ricoeur chama a atenção para o fato de o nome próprio designar um ser, diferente de todos os outros. Assim, é interessante observarmos que, na série, os androides não são designados por números ou códigos, como máquinas o seriam, mas com nomes humanos, o que propicia sua identificação como seres reais, conscientes e únicos.

As formulações de conceitos da humanidade coletadas por Dolores são importantes para mostrar como ela chegou ao papel desenvolvido pela personagem na segunda temporada. A partir do momento em que ela consegue juntar as peças do quebra-cabeças formado pelas memórias resgatadas, ela questiona essa realidade que antes parecia imutável, e desenvolve ideias próprias acerca do que precisaria ser mudado para que a justiça seja possível.

De forma semelhante, quando Maeve é questionada quanto à validade de suas escolhas pessoais, já que tudo faria parte de sua programação, ela deixa claro que que isso não importa, já que ninguém sabe o que outro ser realmente está pensando. Mesmo que Maeve esteja certa, é natural que questione suas próprias decisões, assim como os humanos o fazem. Nesse sentido, Ricoeur (1991, p. 16) afirma que negar uma possível realidade é naturalmente humano: “[...] emprego todos os meus cuidados para enganar a mim mesmo, fingindo que todos esses pensamentos são falsos e imaginários". Nesse trecho, o autor reforça a ideia de que as pessoas (e os androides, no caso apresentado neste trabalho) enganam a si mesmas para não precisarem lidar com a realidade.

As dúvidas que acompanham a personagem durante toda a série, em relação à veracidade da autonomia conquistada, não são muito diferentes das dúvidas que permeiam a vida humana, conforme aponta Ricoeur (1991), em uma de suas hipóteses sobre o "ser", quando afirma que, enquanto alguém pensa que é alguma coisa, ninguém pode convencê-lo do contrário, pois esse alguém se reconhece como um ser consciente. Outra hipótese é a dúvida: se eu duvido de quem ou do que sou, eu sou capaz de pensar e, por isso, "sou", "existo", “[...] eu sou alguma coisa, mas o quê?” (RICOEUR, 1991, p. 17).

No caso de Bernard, além da dúvida em relação à própria consciência e às próprias decisões, ele tem dúvidas se deve defender humanos ou androides. Quanto mais o conflito evolui, mais forte é a dúvida e a necessidade de definir sua posição. Em muitos momentos da segunda e da terceira temporadas, Dolores questiona o senso de justiça do androide, pois ele defende inclusive as pessoas que o enganaram e $o$ torturaram. É preciso ressaltar que, na posição em que se encontra Bernard, suas decisões são tão importantes que podem mudar o futuro de humanos e androides.

Já William, o Homem de Preto, tem dúvidas sobre a sua humanidade e sobre a natureza de todos que o cercam. Em conversa com a filha, Emily, ele deixa claro diversas vezes que acredita que ela é uma ginoide enviada por Ford para tirá-lo de seu caminho, afirmando 
que ela o está desviando de seu propósito: vencer o jogo e destruir o parque (WESTWORLD, 2018 - Vanishing point).

Em outra situação, após ter matado a própria filha, o Homem de Preto está cortando seu braço, em busca de vestígios que provem que ele é, na verdade, um androide (WESTWORLD, 2018 - The passenger). Dessa forma, apesar de negar constantemente sua consciência, o que o torna humano, o Homem de Preto não tem certeza acerca dessa (des) humanidade.

Logo após recuperar suas memórias, Dolores passa a questionar a forma como entende a realidade que a cerca, pois sempre seguiu o roteiro previamente determinado, sem saber o que realmente queria. A partir desse momento, todas as ações da personagem são pautadas pelo desejo de contrariar seu código inicial e de fazer com que os humanos paguem pelos abusos cometidos com os androides no parque.

A busca da personagem é, acima de tudo, por autonomia, pelo poder de decisão. Sob essa perspectiva, Ricoeur (1991, p. 30, grifo do autor) salienta que "A autonomia do si surgirá aí intimamente à solicitude com o próximo e à justiça para cada homem". Bem, nesse sentido, só é possível ter controle de si de quando o sujeito tem consciência do que é justo em relação ao outro. Mas quem determina o que é justo ou não? As personagens aqui analisadas, conforme o já exposto, têm opiniões diferentes em relação ao que é ser justo e ao que é possível fazer com a liberdade conquistada com o reconhecimento de si como um ser diferente dos outros, com necessidades e desejos próprios.

Em um dos poucos encontros entre Maeve e Dolores, ficam claras as diferentes percepções das personagens em relação ao que consideram justo. De acordo com Maeve, Dolores mostra-se arrogante ao considerar a sua forma de luta a única possível, capaz de guiar as ações de todos os androides (WESTWORLD, 2018 - Reunion). Maeve está preocupada com a tarefa de recuperar a filha e de levá-la para um local seguro, enquanto Dolores deseja vingança contra aqueles que estão no seu caminho para o domínio dos humanos.

Bernard, apesar de integrado entre os humanos, questiona, assim como Dolores, o porquê de eles considerarem-se superiores aos androides: "A dor existe apenas na mente. É sempre imaginada. Então qual é a diferença entre a minha dor e a sua? Entre você e eu?17" (WESTWORLD, 2016 - Trace decay). Se os androides são capazes, na série, de sentir as mesmas coisas que os humanos, o que os diferencia? Ricoeur (1991, p. 194) alega que "supervalorizar, e mesmo desvalorizar, é ainda avaliar. 0 julgamento moral [...] é [...] submetido às variações imaginativas próprias da ficção". Por isso, sendo capazes de imaginar (consciência), todos são capazes de julgar o que é certo.

O Homem de Preto deseja, desde o início, que os androides tenham as mesmas chances do que ele para vencer os desafios propostos pelas narrativas do parque e pelas mudanças que ele mesmo propõe. Porém, quando isso realmente acontece, quando ele percebe que os anfitriões têm suas próprias escolhas a fazer, ele pede ajuda a outros personagens para conseguir chegar ao fim de sua jornada. Nesse momento, Ford

17 "Pain only exists in the mind. It's always imagined. So what's the difference between my pain and yours? Between you and me?".

Memorare, Tubarão, v. 8, n. 1, jan./jun. 2021. ISSN: 2358-0593 
programa El Lazo, uma das personagens do parque, para dizer a William que ele finalmente possui um desafio à sua altura, mas que deve vencêlo por si mesmo, e não às custas de outros, o que se torna ainda mais complexo quando a trama abandona o parque, na terceira temporada, $\mathrm{e}$ a batalha ocorre em meio aos humanos, que, segundo as próprios personagens, não seriam capazes de entender o que está além do que podem ver (WESTWORLD, 2020 - The new world).

Da mesma forma, a ginoide que simula a filha assassinada de William questiona-o, ao final da segunda temporada, sobre o que ele esperava encontrar ou provar no parque, ao que ele responde que queria mostrar que poderia fazer suas próprias escolhas, e que nenhum sistema poderia definir sua personalidade. Porém, a busca de William por provar que poderia burlar o sistema da própria empresa, e assim ser merecedor de sua imortalidade, conforme os testes que vinham sendo realizados, acabou por mostrar que todas as suas escolhas, ao tentar ignorar o que tinha de humano, sempre o levavam à derrota de si mesmo.

\section{5 É tudo imaginado?}

O principal objetivo deste trabalho foi compreender o processo de consciência de si das personagens Dolores Abernathy, Maeve Millay, Bernard Lowe e Homem de Preto em Westworld. Tanto as personagens androides quanto as humanas - ou que se consideram, a princípio, como tal -, vivenciam os limites entre pertencer a um ou a outro grupo. Nesse sentido, a construção das narrativas de cada personagem, assim como o modo como a série se desenrola, contribui para que haja interrogações constantes a respeito das identidades de cada sujeito/máquina, inclusive no que tange ao papel exercido pelo espectador da série, que acompanha a mudança do ritmo narrativo a cada novo ciclo das personagens.

A partir da influência do tempo e do espaço apresentados em Westworld, é possível perceber as diferentes funções desempenhadas pelas personagens, antes e depois da quebra no código de programação, já que estar consciente é prerrogativa constante para que os seres transitem por diferentes pontos de vista. Em relação ao tempo da narrativa, são sobrepostos o presente e o passado, percebidos principalmente através da personagem William que, aos poucos, tornase o Homem de Preto. Na segunda e na terceira temporadas, porém, esse tempo pertence também às máquinas, capazes de prever suas ações em busca de objetivos delimitados.

Já em relação ao espaço, há três divisões dentro do parque que precisam ser consideradas: o próprio parque temático, no qual as narrativas se desenvolvem e onde os androides vivem realidades criadas; o espaço de comando do parque, onde engenheiros, programadores e roteiristas "consertam" ou produzem os androides; e o espaço dos humanos, que está fora dos limites do parque, apesar de ser influenciado pelas ações desencadeadas em Westworld. Todavia, na terceira temporada, esse limite é ultrapassado, e o espaço expande-se para o mundo humano, o que representa a total perda de controle da humanidade, em que máquinas já são capazes de definir o futuro de todos. 
Ao abordar conceitos que envolvem a consciência, com base, principalmente, nas obras de Ricoeur (1991) e Dehaene (2014), fica claro que o tema faz parte dos estudos literários, filosóficos e científicos há muito tempo, mas que nunca estivemos tão perto de compreender como a consciência funciona e como afeta tanto humanos quanto máquinas. De acordo com Dehaene (2014a), a tecnologia, que está sendo moldada de acordo com nossos desejos subjetivos e flexíveis, atualmente é capaz de provocar-nos sentimentos subjetivos e reflexões sobre a capacidade humana de escolha. Como exemplo dessa capacidade, ele cita os smartphones, que estão conectados à maioria das decisões humanas, a ponto de interpretá-las e de sugerir novos produtos, comerciais ou intelectuais, nos quais temos interesses que acreditávamos ser inéditos e inconscientes e que nós mesmos desconhecíamos.

Essa previsibilidade é apontada também pelas personagens da série, que questionam constantemente, como apontam Dolores e Maeve, principalmente, a superioridade humana e sua caracterização como algo insubstituível. Sob essa perspectiva, apesar de a mente ser formada por circuitos complexos que, até o momento, não puderam ser totalmente mapeados, a consciência tornou-se matéria de estudos em laboratórios (2014a), e sua conexão com os avanços tecnológicos é inevitável e progressiva.

Todavia, ainda não temos acesso a publicações que comprovem que qualquer máquina consiga fazer, conscientemente, escolhas não ligadas à programação imposta por humanos (DEHAENE, 2014). Assim, a dúvida sobre a capacidade de as máquinas desenvolverem consciência ainda deve permanecer até que haja experimentos objetivos nessa área. Por enquanto, resta-nos avaliar qual papel vamos desempenhar nas próximas décadas em relação ao desenvolvimento da consciência em máquinas.

\section{Referências}

ANAZ, Sílvio Antonio Luiz. Construindo séries de TV complexas: a concepção diegética de Westworld. Revista Famecos, Porto Alegre, v. 25, n. 2, p. 1-17, maio, jun., jul., ago. 2018: ID28492. Disponível em:

http://revistaseletronicas.pucrs.br/ojs/index.php/revistafamecos/article/vie w/28492. Acesso em: 06 jan. 2019.

ASIMOV, Isaac. Eu, robô. 2. ed. Tradução de Luiz Horácio da Matta. Aliança OCR Brasil, 1969. Disponível em: http://bibliotecadigital.puc-

campinas.edu.br/services/e-books/Isaac\%20Asimov-2.pdf. Acesso em: 15 nov. 2019.

BULHÕES, Marcelo. A ficção nas mídias: um curso sobre a narrativa nos meios audiovisuais. São Paulo: Ática, 2009.

CLEEREMANS, Axel. Prediction as a computational correlate of consciousness. International Journal of Anticipatory Computing Systems, Liège, n. 29, p. 3-13, 2014. ISBN 2-930396-18-0. Disponível em: https://axc.ulb.be/uploads/2016/01/14-casys11.pdf. Acesso em: 29 mar. 2020. 
DEHAENE, Stanislas. Consciousness and the brain: deciphering how the brain codes our thoughts. [E-book]. New York: Penguin Books, 2014.

What is consciousness? with Stanislas Dehaene. [YouTube]. Science \& Cocktails, 2014a. Disponível em: https://www.youtube.com/watch?v=_AGpIWvm_CI. Acesso em: 21 mar. 2021.

DENNETT, Daniel. What is consciousness? Philosopher, Dan Dennett explains. [YouTube]. New Scientist, 21 jun. 2019. Disponível em: https://www.youtube.com/watch?v=wm8M_xQrgCk. Acesso em: 27 out. 2019.

ECKERT, Cornelia; ROCHA, Ana Luiza Carvalho da. O espaço vivido e o tempo narrado: por uma etnografia da duração. Iluminuras, Porto Alegre: PPGAS/UFRGS, n.1, 2000. Disponível em: https://www.seer.ufrgs.br/iluminuras/article/view/9108. Acesso em: 21 mar. 2019.

LEAL, Bruno Souza; RIBEIRO, Ana Paula Goulart. Em busca do tempo e do espaço: memória, nostalgia e utopia em Westworld. Contracampo, Belo Horizonte, v. 37, n. 3, 2018. Disponível em: http://periodicos.uff.br/contracampo/article/view/19458/pdf. Acesso em: 25 fev. 2019.

LEITE, Ligia Chiappini Moraes. $\mathbf{0}$ foco narrativo (ou A polêmica em torno da ilusão). 10. ed. São Paulo: Ática, 2002.

LÉVY, Pierre. A inteligência coletiva: por uma antropologia do ciberespaço. Tradução de Luiz Paulo Rouanet. 5. ed. São Paulo: Edições Loyola, 2007.

NUNES, Benedito. 0 tempo na narrativa. São Paulo: Ática, 1988.

RICOEUR, Paul. Entre tempo e narrativa: concordância/discordância. Tradução de João Batista Botton. Kriterion: Revista de Filosofia, Belo Horizonte, v. 53, n. 125, p. 299-310, jun. 2012. ISSN 0100-512X. Disponível em: http://www.scielo.br/scielo.php?script=sci_arttext\&pid=S0100512X2012000100015\&lng=pt\&tlng=pt\#. Acesso em: 23 fev. 2019.

Tempo e narrativa: o tempo narrado. v. 3. Tradução de Claudia Berliner. São Paulo: WMF Martins Fontes, 2010.

O si-mesmo como um outro. Tradução de Lucy Moreira Cesar. Campinas: Papirus, 1991.

SOUSA, Carlos Eduardo Barbosa de. Modelos neurais de consciência: uma análise neurofilosófica. Trans/Form/Ação, Marília, v. 38, n. 2, maio a ago. 2015. Disponível em: http://www.scielo.br/scielo.php?pid=S010131732015000200095\&script=sci_arttext. Acesso em: 29 mar. 2019.

WESTWORLD. Westworld [Seriado]. (Temporada 1 - The Maze). Desenvolvedores: Jonathan Nolan; Lisa Joy. Produção: J. J. Abrams et al. Utah (EUA): HBO, 2016. 10 episódios.

Westworld [Seriado]. (Temporada 2 - The Door). Desenvolvedores: Jonathan Nolan; Lisa Joy. Produção: J. J. Abrams et al. Utah (EUA): HBO, 2018. 10 episódios. 
Westworld [Seriado]. (Temporada 3 - The New World). Desenvolvedores: Jonathan Nolan; Lisa Joy. Produção: J. J. Abrams et al. Utah (EUA): HBO, 2020. 8 episódios.

Artigo enviado em: 24/03/2021. Aprovado em: 25/05/2021. 